\title{
Fabrication of Multilayers Film of Myoglobin and Glutaraldehyde on the Surface of Gold Electrode Based on Covalent Interaction and Its Application
}

\author{
Yuzhong Zhang*, Yuehong Wang, Shaojun Zhang, Liping Zhang
}

College of Chemistry and Materials Science, Anhui Normal University, Wuhu, P.R. China

*Corresponding Author

Yuzhong Zhang

College of Chemistry and Materials Science

Anhui Normal University

Wuhu 241000, P.R. China

Tel: +86-553-3869303

Fax: +86-553-3869303.

E-mail: zhyz65@mail.ahnu.edu.cn

Received: 1 March 2011; | Revised: 30 April 2011; | Accepted: 9 May 2011

\begin{abstract}
In this work, the multilayers film of myoglobin $(\mathrm{Mb})$ and glutaraldehyde $(\mathrm{GA})$ was assembled on the surface of gold electrode modified with MWCNTs by layer by layer (LBL) assembly technique, and the assembly process was characterized by cyclic voltammetry (CV) and UV-Vis spectroscopy. UV-Vis spectroscopy showed that $\mathrm{Mb}$ in the multilayers film retained its native biology activity, and the multilayers film exhibited good electrocatalytic activity toward reduction of $\mathrm{H}_{2} \mathrm{O}_{2}$ in $\mathrm{pH} 7.0$ phosphate buffer solution (PBS), the currents intensity were linearly with concentrations of $\mathrm{H}_{2} \mathrm{O}_{2}$ in the range of $6 \times 10^{-6}$ to $8.4 \times 10^{-5} \mathrm{M}$ with the detection limit of $5 \times 10^{-7} \mathrm{M}(\mathrm{S} / \mathrm{N}=3)$. The Michaelis-Menten constant was $0.115 \mathrm{mM}$. In addition, interference experiments showed no interference response obtained for dopamine, ascorbic acid, ethanol, uric acid species et al at this working potential.
\end{abstract}

Keywords: Myoglobin; Glutaraldehyde; Multiwall carbon nanotubes; Layer-by-layer assembly technique.

\section{Introduction}

Myoglobin $(\mathrm{Mb})$ is a $16.7 \mathrm{k}$ Da heme protein in muscle tissues which the functions to store and transport oxygen. It contains a single polypeptide chain with an iron heme as its prosthetic group. Studies of electrochemical behavior of heme proteins are essential for a fundamental understanding of their biological activity. $\mathrm{Mb}$ is an ideal molecule for the study of electron -transfer reactions of heme proteins and also for biosensing and electrocatalysis [1]. Although $\mathrm{Mb}$ possesses functional groups that can be readily oxidized or reduced by chemical redox agents, it does not easily undergo facile redox reactions in solution with bare or "naked" solid electrodes, this is because unfavorable orientation of the protein on electrode surface may increase the distance between its heme redox center and electrode 
surface. Another reason for the difficulty of electron exchange may be the adsorption of impurities in the protein solution on the surface of electrodes. The adsorption of the impurities or denatured protein can block the electron communication between heme and electrode. So facilitation of the electron transfer between $\mathrm{Mb}$ and electrode is very challenging, $\mathrm{Li}$ and his coworker have studied the kinetics of hemoglobin electron transfer in solution and immobilized on electrode surface with electrochemical and spectroscopy $[2,3]$. Hence, to explore methods to increase the electron transfer rate between $\mathrm{Mb}$ and the electrode, much effort have been devoted to the characterization of the electrochemistry of $\mathrm{Mb}$ using various films [4, 5]. Hu's and Rusling's groups have provided a lot of good work in this area $[6,7]$. From the publish literature, most of work about the direct electrochemistry of Mb was performed at monolayer film. The film has low $\mathrm{Mb}$ content and poor stability for preparing sensor.

In recent years, LBL assembly as a relatively new film-forming technique has been developed rapidly due to its procedure simplicity, wider selectivity and controlled thickness from nanometer to micrometer scale. As a result, LBL assemble technique has attracted much attention in various research field. To date, there are various LBL methods have been reported, including electrostatic interaction [8], hydrogenbonding [9], charge-transfer interaction [10] and coordination bonding [11, 12]. Multilayer films containing protein [13-14] or nanoparticles (NPs) [15] and carbon nanotubes (CNTs) [16-23] via LBL assemble technique have been reported. Such as, $\mathrm{Ju}$ and his co-works [22] have fabricated a multilayers film composed of GNPs, MWCNTs, and glucose oxidase (GOD); Dong and his coworks [23] has assembled PDDA, MWCNTs and platinum nanoparticles( Pt NPs) multilayers film. Our groups have fabricated multilayers film composed of $\mathrm{Mb}$, chitosan, and polyelectrolytewrapped MWCNTs [24]. All the above mentioned multilayers film is obtained via electrostastic interaction. As we know, electrostatic interaction is a weak interaction force, which the stability of assembled films is poor. To overcome this drawback, the LBL covalent attachment technique provides a platform because covalent interaction is stronger. So the assembled film has higher stability.

In this work, we want to fabricate multilayers film of $\mathrm{Mb}$ based on covalent attachment mode, and investigate the direct electrochemistry of $\mathrm{Mb}$ and electrocatalytic activity towards the reduction of $\mathrm{H}_{2} \mathrm{O}_{2}$, and aim to fabricate a sensitive electrochemical biosensor of $\mathrm{H}_{2} \mathrm{O}_{2}$. Chitosan (CS), derived from chitin via deacetylation with alkali is a linear copolymer of glucosamine and $\mathrm{N}$ acetylglucosamine units. It displayed an excellent film-forming ability, good adhesion, biocompatibility and low toxicity. It is easy to take Schiff's reaction with glutaraldehyde (GA) because it contains $\mathrm{NH}_{2}$ groups. The multilayers film of $\mathrm{Mb}$ assembled process is follows: First, GA was covalent attachment matrix of MWCNTsCS composite based on Schiff's reaction. Next, $\mathrm{Mb}$ was covalent attachment with GA, and multiple repetition of the assemble process leads to form multilayers of $\mathrm{Mb}$. The assemble process was conformed by $\mathrm{CV}$ technique and $\mathrm{UV}-\mathrm{V}$ is spectroscopy. Final, we investigated the electrocatalytic activity towards reduction of $\mathrm{H}_{2} \mathrm{O}_{2}$ by the multilayers film modified electrode.

\section{Experimental}

\subsection{Reagents and apparatus}

MWCNTs were purchased from Chengdu Institute of Organic Chemistry, Chinese Academy of Sciences and used without further purification (purity $>90 \%$ ). CS, GA (50\%) and Mb were from Sigma and used as received. Other chemicals were of analytical reagent grade. $0.1 \mathrm{M}$ phosphate buffer solution (PBS) was prepared by mixing the stock standard solutions of $\mathrm{K}_{2} \mathrm{HPO}_{4}$ and $\mathrm{KH}_{2} \mathrm{PO}_{4}$, all containing $0.1 \mathrm{M} \mathrm{NaCl}$. The $\mathrm{pH}$ was adjusted with $0.1 \mathrm{M} \mathrm{H}_{3} \mathrm{PO}_{4}$ or $0.1 \mathrm{M} \mathrm{NaOH}$.

A $5.0 \mathrm{mg} / \mathrm{mL} \mathrm{CS}$ was prepared by dissolving $50 \mathrm{mg} \mathrm{CS}$ in $10 \mathrm{~mL} 0.05 \mathrm{M} \mathrm{HCl}$, and the $\mathrm{pH}$ of the solution was adjusted to 5.0 with $\mathrm{NaOH}$; Suitable mount of MWCNTs were dispersed in $5.0 \mathrm{mg} / \mathrm{mL} \mathrm{CS}$ with the help of sonication for $1 \mathrm{~h}$. The accurate concentration of $\mathrm{H}_{2} \mathrm{O}_{2}$ was determined by titration with potassium permanganate solution. All solutions were prepared with double-distilled deionized water. 
Cyclic voltammetry (CV) and amperometry experiments were performed using a CHI660A electrochemical workstation (Shanghai Chenhua Instruments Co., China). The three-electrode system consisted of the working electrode of interest, a saturated calomel electrode (SCE) reference electrode, and a platinum wire auxiliary electrode. UV-Vis spectroscopy was performed using a U-3010 spectrophotometer (Hitachi, Tokyo, Japan). All experiments were performed at ambient temperature.

All solutions were deoxygenated by bubbling high-purity nitrogen for $30 \mathrm{~min}$, and nitrogen atmosphere was kept over the solution during measurements. All potentials in this work are reported referenced to the SCE.

\subsection{Multilayers film of Mb assembly process}

Prior to use, Au electrode ( $\mathrm{d}=2 \mathrm{~mm})$ was pretreated according to literature [25].Then it was modified with $1 \mu \mathrm{L}$ of MWCNTs dispersion and to dry at ambient temperature. The MWCNTs film modified electrode was immersed in $10 \%$ GA for $6 \mathrm{~h}$ and $4 \mathrm{mg} / \mathrm{mL} \mathrm{Mb}$ for $6 \mathrm{~h}$ alternately at room temperature, the process was repeated until demand layers. During the film assembly process, the aldehyde groups of GA and the amine groups of $\mathrm{CS}$ or $\mathrm{Mb}$ would take Schiff reaction and formed a new bond $\mathrm{C}=\mathrm{N}$. Thus, the multilayers film $(\mathrm{GA} / \mathrm{Mb})_{\mathrm{n}}$ was successfully assembled on the MWCNTs film. The assemble process was shown in Scheme.1.

\section{Results and Discussion}

\subsection{The Characterization of the Multilayer Film}

In experiments, CVs was used to monitor the growth of $(\mathrm{GA} / \mathrm{Mb})_{\mathrm{n}}$ films. Fig. 1 showed the CVs of different film in $\mathrm{pH}$ 7.0. No redox peak can be observed at bare $\mathrm{Au}$ electrode (curve a) or MWCNTs film modified Au electrode (curve b). However, a pair of well-defined and symmetrical redox peak can be observed at Mb/GA/ MWCNTs -CS film-modified electrode (curve c), whose formal potential was at about $-0.3 \mathrm{~V}$. The redox peak was from reduction and oxidation of $\mathrm{Mb}$ heme $(\mathrm{Fe}(\mathrm{III}) / \mathrm{Fe}(\mathrm{II}))$ in films. The electrode reaction is follow:

\section{MbhemeFe $($ III $)+e+H^{+}=$MbhemeFe $\quad($ II $)$}

Further, the peak currents of the reduction and oxidation of $\mathrm{Mb}$ are increased nonlinearly with the number of mutilayers (n) increased from 1 to 6 , and then it kept a constant when $n>6$.

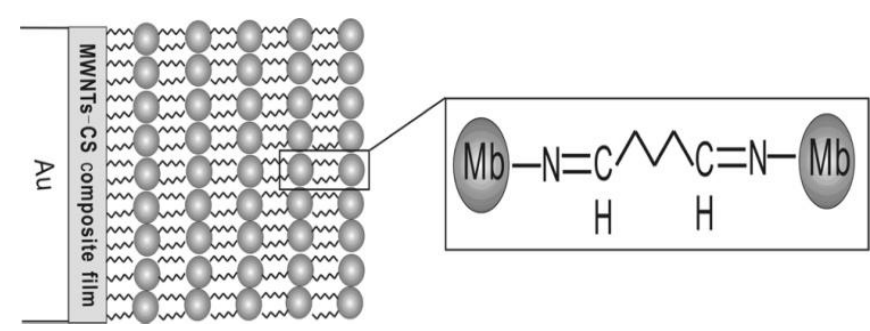

Scheme 1. Schematic representation assembly process of the multi-films

The Soret band of heme protein is usually an indicator of the microenvironment where heme center locates. This peak will be diminished if the protein is denatured. Fig. 2 showed UV-Vis spectroscopy of different films, From Fig. 2, we obviously observed an absorption peak of $\mathrm{Mb}$ at $410 \mathrm{~nm}$, suggesting that $\mathrm{Mb}$ in films has a secondary structure nearly the same as the native state of $\mathrm{Mb}$ [26], and the absorb intensity increased linearly with the number of Mb bilayers (inset), indicting $(\mathrm{GA} / \mathrm{Mb})_{\mathrm{n}}$ film was successful fabricated on the surface of the glassy carbon electrode. In this work, we select $(\mathrm{GA} / \mathrm{Mb})_{6}$ film for the next electrochemical experiment.

\subsection{Effect of scan rate and $\mathrm{pH}$}

Effects of scan rate and $\mathrm{pH}$ on voltammetric response of multilayers film have been investigated. It was obviously observed that the peak currents increased linearly with scan rate from 50 to $1000 \mathrm{mV} \mathrm{s}^{-1}$ (data is not shown), indicating that the electrode reaction was surfacecontrolled electrode process. Fig. 3 showed the $\mathrm{CVs}$ of $(\mathrm{GA} / \mathrm{Mb})_{6}$ multilayer film at various $\mathrm{pH}$. It was clearly observed that peak potentials of $\mathrm{Mb}$ both cathodic and anodic shifted linearly negatively with increasing $\mathrm{pH}$ of solution from 5.0 to 9.0 , the reason was attributed to proton participate in the electrode reaction, and the formal potential had linear relationship with $\mathrm{pH}$ of 
solution, the linear regression equation is $\mathrm{E}^{\circ \prime}(\mathrm{V})=$ $0.0501-0.057 \mathrm{pH}$ with the correlation coefficient of 0.9940. Additionally, all changes as $\mathrm{pH}$ were reversible. For example, the $\mathrm{CVs}$ of the $(\mathrm{GA} / \mathrm{Mb})_{6}$ film modified electrode at $\mathrm{pH} 8.0$ buffer was reproduced after immersion in $\mathrm{pH} 5.0$ buffer and then returned to the $\mathrm{pH} 8.0$ buffer. In this work, $\mathrm{pH} 7.0$ solution was select for the following electrochemical experiments.

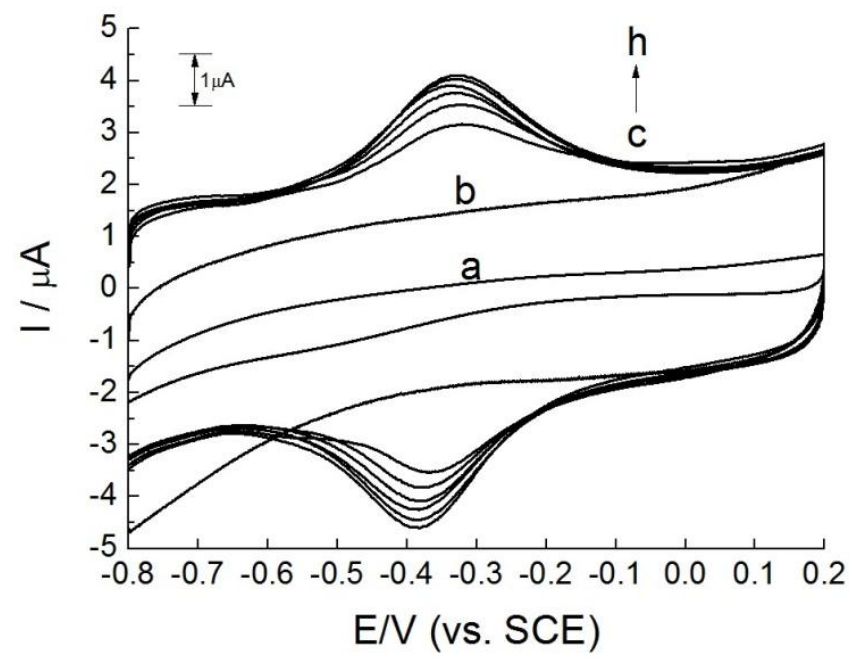

Figure 1. Cyclic voltammograms of different modified electrodes in $0.1 \mathrm{M}$ PBS ( $\mathrm{pH} 7.0$ ) at $100 \mathrm{mV} \mathrm{s}^{-1}$ : (a) bare $\mathrm{Au},(\mathrm{b}) \mathrm{MWCNTs}-\mathrm{CS} / \mathrm{Au},(\mathrm{c})$ to (h) represented 1 to 6 bilayers, respectively.

\subsection{Electrocatalytic activity towards reduction of $\mathrm{H}_{2} \mathrm{O}_{2}$}

In order to investigate the electrocatalytic activity of $\mathrm{Mb}$ in the multilayers film, $\mathrm{H}_{2} \mathrm{O}_{2}$ was selected for target, and the electrocatalytic activity of $\mathrm{H}_{2} \mathrm{O}_{2}$ was investigated by $\mathrm{CV}$ and amperometry technique. As shown in Fig. 4A, with the addition of $\mathrm{H}_{2} \mathrm{O}_{2}$, the reduction peak current was enhanced corresponding with the decrease of the oxidation peak current. The reduction peak current was increased with the concentration of $\mathrm{H}_{2} \mathrm{O}_{2}$ increased in solution. Fig. 4B displayed a typical hydrodynamic amperometry cure of the multilayer films modified electrode for successive injection of different volume $\mathrm{H}_{2} \mathrm{O}_{2}$. From Fig. 4B, we can observe that the magnitude of the current increases with the successive injection of $\mathrm{H}_{2} \mathrm{O}_{2}$ successive. The response currents were linear with concentration of $\mathrm{H}_{2} \mathrm{O}_{2}$ from $6.0 \times 10^{-6}$ to $8.4 \times 10^{-5}$
M, with a correlation coefficient of 0.9994 (Fig. $4 \mathrm{C})$. The detection limit of $5.0 \times 10^{-7} \mathrm{M}(\mathrm{S} / \mathrm{N}=3)$ was obtained.

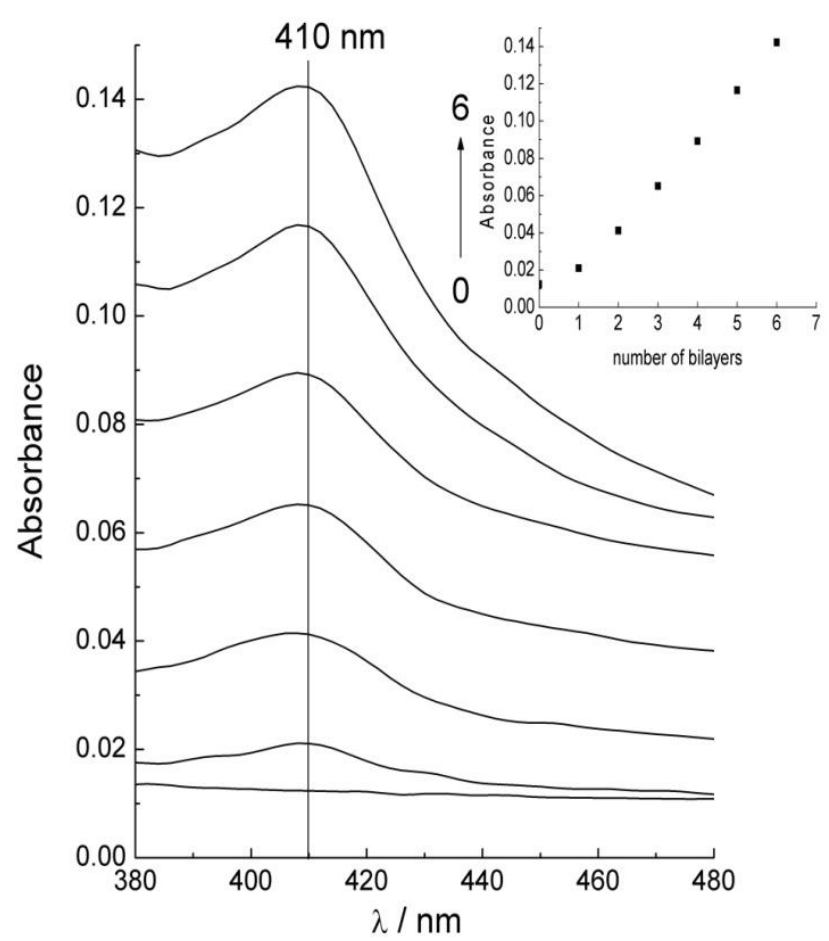

Figure 2. UV-vis spectra for $(\mathrm{GA} / \mathrm{Mb})_{\mathrm{n}}$ films on the quartz slides with varying number from 0 to 6 . Inset: Plot of the absorbence vs. the number of bilayers (n)

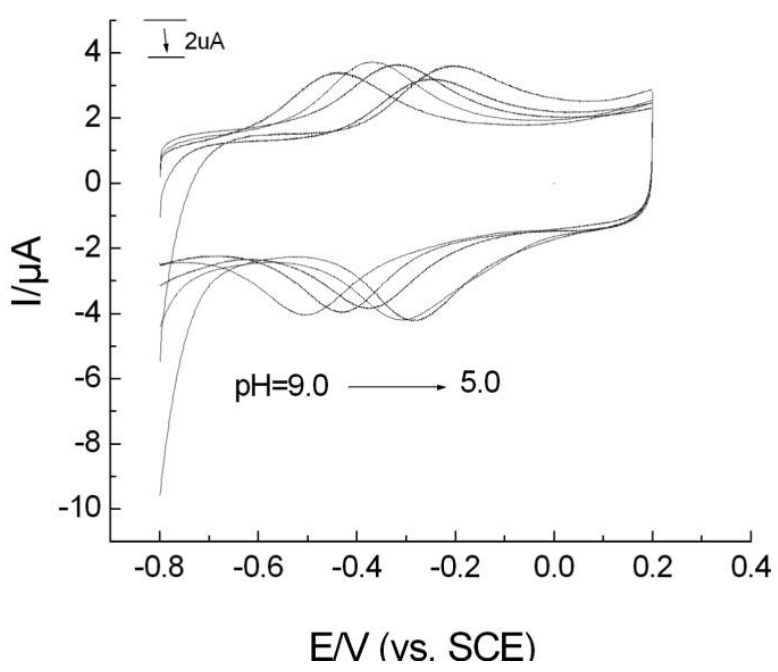

Figure 3. Cyclic voltammograms of the $(\mathrm{GA} / \mathrm{Mb})_{6}$ film modified electrode at different $\mathrm{pH} . v=100 \mathrm{mV} \mathrm{s}^{-1}$. 
A
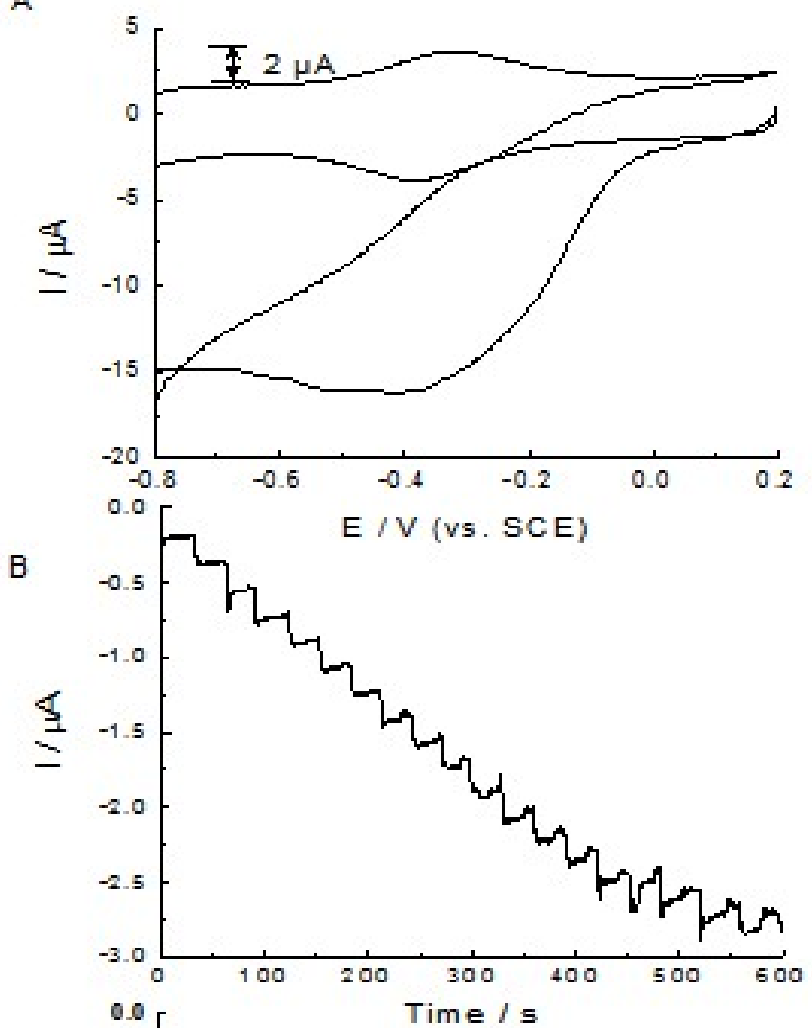

C
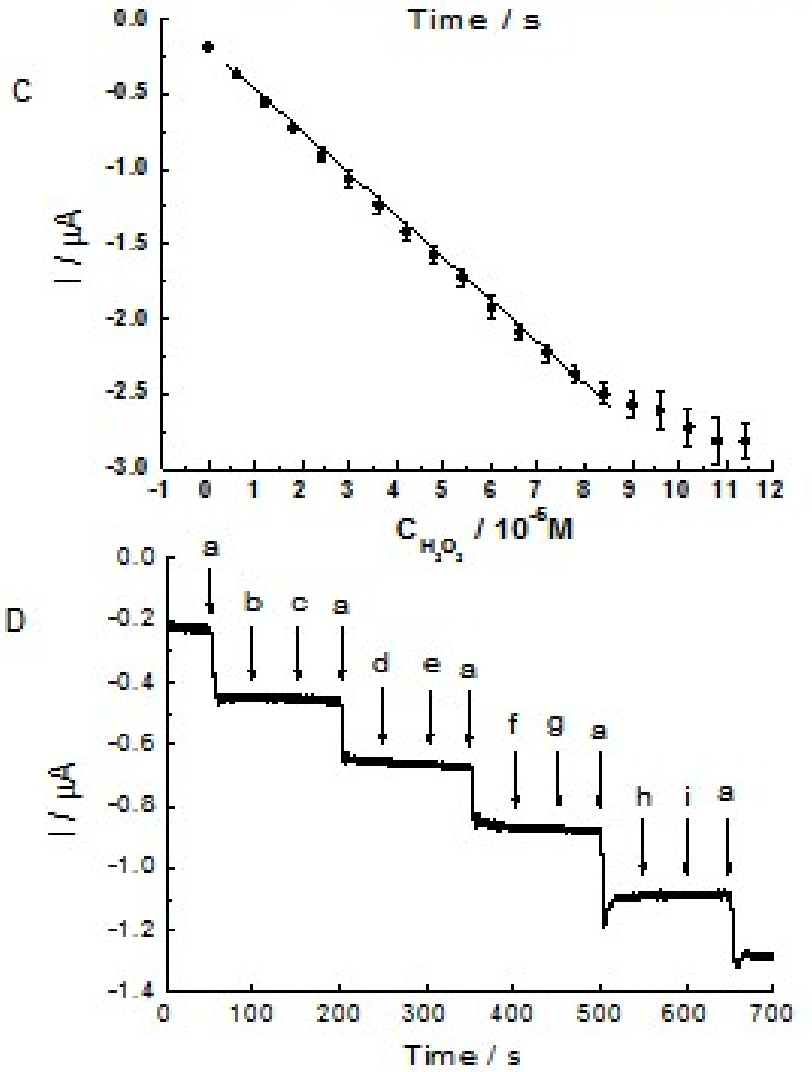

Figure 4. (A) Cyclic voltammograms of the $(\mathrm{GA} / \mathrm{Mb})_{6}$ film modified electrode in $\mathrm{pH} 7.0$ buffers with (a) $0 \mathrm{M}$; (b) $8 \times 10^{-5} \mathrm{M} \mathrm{H}_{2} \mathrm{O}_{2}$ at $100 \mathrm{mV} \mathrm{s}^{-1}$.

(B) The hydrodynamic response of the film modified electrode in $\mathrm{pH} 7.0$ PBS upon additions of $6.0 \mu \mathrm{M}$ $\mathrm{H}_{2} \mathrm{O}_{2}$ every $30 \mathrm{~s}$ at potential of $-0.350 \mathrm{~V}$.
(C) the plots of current vs concentrations of $\mathrm{H}_{2} \mathrm{O}_{2}$

(D) The hydrodynamic response of the $(\mathrm{GA} / \mathrm{Mb})_{6}$ modified electrode in $\mathrm{pH}$ 7.0 PBS upon additions of $0.01 \mathrm{mM} \mathrm{H} \mathrm{H}_{2}$ (a), $1 \mathrm{mM}$ ascorbic acid (b), $0.1 \mathrm{mM}$ dopamine (c), $0.1 \mathrm{mM}$ uric acid (d), $0.5 \mathrm{mM}$ glucose (e), $0.05 \mathrm{mM} \mathrm{L}^{-1}$ tyrosine (f), $0.1 \mathrm{mM}$ catechol $(\mathrm{g})$, $3.0 \mathrm{mM}$ ethanol (h), $10 \mathrm{mM} \mathrm{Cd}^{2+}(\mathrm{i})$.

\subsection{Interference Study}

The interference experiments were investigated using amperometry. In this work, the interference species were select as ascorbic acid, dopamine, uric acid, glucose, L-tyrosine, catechol, ethanol, $\mathrm{Cd}^{2+}$. Although dopamine, ascorbic acid, ethanol, uric acid and catechol are electroactive substances, their oxidation potential are higher than that of $\mathrm{Mb}$, at the meantime, these substance oxidation signal can be separated from that of $\mathrm{Mb}$, glucose, L-tyrosine have nooxidation signal in this window, so these substance should not be interfered in the determination of $\mathrm{H}_{2} \mathrm{O}_{2}$. Our judgments were conformed by experiment results and the results were shown in Fig.4D. From Fig. 4D, it was obviously observed that no interference response was obtained for these species at this working potential, which show that the multilayer films modified electrode can be used to detect $\mathrm{H}_{2} \mathrm{O}_{2}$ in presence of this interfering species.

\subsection{Stability}

The stability of $(\mathrm{GA} / \mathrm{Mb})_{6}$ multilayer film was also tested by $\mathrm{CV}$ with two different methods. In the solution studies (method I), the modified electrode were stored in a buffer solution all the time, and $\mathrm{CVs}$ were measured periodically. Alternatively, with method II, the modified electrode was stored in air, and CVs were run periodically after returning the dried electrodes to a buffer solution. The results of method I showed that the peak currents gradually decreased as the storing time increased. However, the peak currents retained about $95 \%$ of the initial response after a two week's storage. With method II, the voltammetric response hardly decreased after 50 cycles. Hence, the multilayer film of $(\mathrm{GA} / \mathrm{Mb})_{\mathrm{n}}$ had a better stability. The reason is attributed to a stronger interaction force of $\mathrm{GA}$ and $\mathrm{Mb}$, and it is easy for Mb not to lose during experiments. 


\subsection{Determination of the Michaelis-Menten constant}

The determination of Michaelis-Menten constant was following: when the concentration of $\mathrm{H}_{2} \mathrm{O}_{2}$ further increased, the calibration curve tended to lever off. A response plateau was obtained, showing the characteristics of the Michaelis-Menten kinetic mechanism. To obtain $K_{\mathrm{m}}$, which gives an indication of the enzymesubstrate kinetics, one can use the LineweaverBurk equation [27]

$$
\frac{1}{I_{s s}}=\frac{1}{I_{\max }}+\frac{K_{m}}{I_{\max } C}
$$

Here, $I_{\mathrm{ss}}$ is the steady-state current after the addition of $\mathrm{H}_{2} \mathrm{O}_{2}, I_{\max }$ is the maximum current measured under saturated $\mathrm{H}_{2} \mathrm{O}_{2}$ solution and $C$ is the $\mathrm{H}_{2} \mathrm{O}_{2}$ concentration. The $\mathrm{K}_{m}$ in this work was calculated as $0.115 \mathrm{mM}$. It is well known that a smaller $K_{m}$ represents a higher catalytic ability. This value was lower than some $\mathrm{H}_{2} \mathrm{O}_{2}$ sensors based on HRP [28-29]. The low value of $K_{\mathrm{m}}$ indicates that the modified electrode possesses properties of an excellent performance biosensor for the determination of $\mathrm{H}_{2} \mathrm{O}_{2}$.

\section{Conclusions}

Multilayers film of $(\mathrm{GA} / \mathrm{Mb})_{6}$ have been fabricated on the matrix of MWCNTs-CS composite on $\mathrm{Au}$ electrode via LBL covalent mode. The assembly process was investigated by $\mathrm{CV}$ and $\mathrm{UV}-\mathrm{Vis}$ spectroscopy. Mb in film kept its biology activity. Moreover, the multilayers film modified electrode exhibited excellently electrocatalytic activity towards the reduction of $\mathrm{H}_{2} \mathrm{O}_{2}$, indicating the potential application as an $\mathrm{H}_{2} \mathrm{O}_{2}$ biosensor.

\section{Acknowledgements}

We thank the National Nature Science Foundation of China (No. 20675002), which financially supported this work.

\section{References}

[1] L. J. Ye., R.P. Baldwin., Catalytic reduction of myoglobin and hemoglobin at chemically modified electrodes containing methylene blue. Anal.Chem.,1988, 60, 2263-2268. DOI: 10.1021/ac00171a021

[2] C.Z. Li, K. Nishiyama, I. Taniguchi, Electrochemical and spectroelectrochemical studies on cobalt myoglobin, Electrochim Acta, 2000, 45: 2883-2888. DOI: 10.1016/S0013-4686(00)00363-7

[3] C.Z. Li, G.D Liu, S.H. Prabhulkar, Comparison of kinetics of hemoglobin electron transfer in solution and immobilized on electrode surface, Am J. Biome.Sci, 2009.1.303-311. DOI: 10.5099/aj090400303

[4] Q. L. Wang, G. X.Lu, B. J. Yang, Myoglobin/sol-gel film modified electrode: direct electrochemistry and electrochemical catalysis, Langmuir, 2004, 20,1342-1347.DOI: 10.1021/la035321d

[5] A.E.F. Nassar, Z. Zhang, N. F. Hu, J. F. Rusling, Proton coupled electron transfer from electrodes to myoblin in ordered biomembrane-like film. J. Phys. Chem. B, 1997,101(12),2224-2231.DOI: $10.1021 / \mathrm{jp} 962896 \mathrm{t}$

[6] Y.L Zhou, N.F Hu, Y.H.Zeng, J. F. Rusling, Heme protein-clay films: direct electrochemistry and electrochemical catalysis, Langmuir, 2002, 18 (1), 211-219. DOI: 10.1021/la010834a

[7] N.Fi Hu, J. F. Rusling, Electrochemistry and catalysis with myoglobin in hydrated poly(ester sulfonic acid) ionomer films, Langmuir, 1997, 13, 4119-4125. DOI: $\underline{10.1021 / 1 \mathrm{a} 970129 \mathrm{v}}$

[8] J.J. Feng, G. Zhao, J.J. Xu, H.Y. Chen. Direct electrochemistry and electrocatalysis of heme proteins immobilized on gold nanoparticles stabilized by chitosan. Anal. Biochem. 2005, 342(2):280-286.DOI:10.1016/j.ab.2005.04.040

[9] L.Y. Wang, Z.Q. Wang, X. Zhang, J. C. Shen, L.F. Chi, H. Fuchs. A new approach for the fabrication of an alternating multilayer film of poly(4-vinylpyridine) and poly(acrylic acid) based on hydrogen bonding. Macromol. Rapid Commun. 1997, 18(6): 509-514. DOI: 10.1002/marc.1997.030180609 
[10] Y. Shimazaki, M. Mitsuishi, S. Ito, M .Yamamoto. Preparation of the layer-by-layer deposited ultrathin film based on the chargetransfer interaction. Langmuir, 1997, 13(6):1385-1387. DOI: 10.1021/la9609579

[11] H. M. Xiong, M. H. Chen, Z. Zhou, X. Zhang, J. C. Shen. A new approach to the fabrication of a selforganizing film of heterostructured polymer $/ \mathrm{Cu}_{2} \mathrm{~S}$ nanoparticles. Adv. Mater. 1998, 10(7):529-532. DOI: 10.1002/(SICI)1521-4095(199805)10:7

[12] M. Schütte, D.G. Kurth, M. R. Linford, H. Cölfen, H. Möhwald.Metallosupramolecular thin polyelectrolyte films. Angew. Chem. Int. Ed., 1998, 37(20):2891-2893. DOI:10.1002 / (SICI) 1521-3773 (19981102) 37:20

[13] L.W. Wang, N.F. Hu. Direct electrochemistry of hemoglobin in layer-by-layer films with poly(vinyl sulfonate) grown on pyrolytic graphite electrodes. Bioelectrochem., 2001, 53(2):205-212. DOI: 10.1016 / S0302-4598 (01) 00095-2

[14] P.L. He, N.F Hu, J.F. Rusling. Driving forces for layer-by-layer self-assembly of films of $\mathrm{SiO}_{2}$ nanoparticles and heme proteins. Langmuir, 2004, 20 (3): 722-729. DOI: 10.1021/la035006r

[15] D.F. Cao, N.F. Hu. Direct electron transfer between hemoglobin and pyrolytic graphite electrodes enhanced by $\mathrm{Fe}_{3} \mathrm{O}_{4}$ nanoparticles in their layer-by-layer self-assembly films. Biophys. Chem., 2006, 121(3) :209-217. DOI: 10.1016/j.bpc.2005.11.003

[16] J. H. Rouse, P.T. Lillehei. Electrostatic assembly of polymer/single walled carbon nanotube multilayer films. Nano Lett., 2003, 3(1): 59-62. DOI: $10.1021 / \mathrm{nl} 025780 \mathrm{j}$

[17] A.A. Mamedov, N.A. Kotov, M. Prato, D.M. Guldi, J.P. Wicksted, A. Hirsch. Molecular design of strong single-wall carbon nanotube/polyelectrolyte multilayer composites. Nat. Mater., 2002, 1:190-194. DOI: $10.1038 /$ nmat747

[18] X.Wang, H.X.Huang, A.R. Liu, B. Liu, T. Wakayama, C. Nakamura, J. Miyake, D.J. Qian. Layer-by-layer assembly of single-walled carbon nanotube-poly(viologen) derivative multilayers and their electrochemical properties. Carbon, 2006, 44:2115-2121.DOI:10.1016/j.carbon.2006.04.014

[19] B.S. Shim, N.A. Kotov. Single-Walled Carbon Nanotube Combing during layer-bylayer Assembly: From random adsorption to aligned composites. Langmuir, 2005, 21(21): 9381-9385. DOI: 10.1021/la050992s

[20] A. Ishibashi, Y. Yamaguchi, H. Murakami, N. Nakashima. Layer-by-layer assembly of RNA/single-walled carbon nanotube nanocomposites. Chem. Phys. Lett., 2006, 419:574-577.DOI:10.1016/j.cplett.2005.11.122

[21] M.H. Yang, Y. Yang, H.F. Yang, G.L. Shen, R.Q.Yu. Layer-by-layer self-assembled multilayer films of carbon nanotubes and platinum nanoparticles with polyelectrolyte for the fabrication of biosensors. Biomaterials, 2006, 27(2):246255.DOI:10.1016/j. biomaterials. 2005.05.077

[22] H.T Zhao, H.X. Ju. Multilayer membranes for glucose biosensing via layer-by-layer assembly of multiwall carbon nanotubes and glucose oxidase. Anal. Biochem. 2006, 350 (1):138-144. DOI: 10.1016/j.ab.2005.11.034

[23] Y. Liu, X.H. Qu, H.W. Chen, B.F Liu, S.J. Dong. Facile preparation of amperometric laccase biosensor with multifunction based on the matrix of carbon nanotubes-chitosan composite. Biosen. Bioelectron, 2006, 21(12):2195-2201.DOI: 10.101j.bios.2005.11.014

[24] L. P. Zhang, W.J. Gong, Y. Pan, Y.Z. Zhang. Fabrication of multilayer film modified gold electrode composed of myoglobin, chitosan, and polyelectrolyte wrapped multi-wall carbon nanotubes by layer-by-layer assembled technique and electrochemical catalysis for hydrogen peroxide and trichloroacetic acid. R. J. Electrochem., 2008, 44 (11):1271. DOI: 10.1134/S1023193508110128

[25] Y.Z.Zhang. K.Y. Zhang, H.Y.Ma , Electrochemical DNA biosensors based on gold nanoparticles / cysteamine/ poly(glutamic acid) modified electrode, Am. J. Biomed. Sci. 2009, 1(2), 114-124. DOI: 10.5099/aj090200115

[26] Y.M. Lvov, Z.Q. Lu, J.B. Schenkman, X.L. $\mathrm{Zu}$, J.F. Rusling. Direct electrochemistry of myoglobin and cytochrome $\mathrm{P}_{50} 0_{\text {cam }}$ in alternate layer-by-layer films with DNA and other polyions. J. Am. Chem. Soc. 1998, 120(17):4073-4080. DOI: 10.1021/ja9737984

[27] R.A. Kamin, G.S. Willson. Rotating ringdisk enzyme electrode for biocatalysis kinetic studies and characterization of the 
immobilized enzyme layer. Anal. Chem., 1980,52(8):1198-1205.DOI:10.1021/ ac50058a010

[28] T. Tangkuaram, C. Ponchio, T. Kangkasomboon, P. Katikawong, W. Veerasai. Design and development of a highly stable hydrogen peroxide biosensor on screen printed carbon electrode based on horseradish peroxidase bound with gold nanoparticles in the matrix of chitosan. Biosens. Bioelectron,
2007, 22(9)2071-2078. DOI: 10.1016 / j. bios. 2006.09 .011

[29] Z. Tonga, R. Yuan, Y. Chai, Y. Xie, S. Chen. A novel and simple biomolecules immobilization method: Electro-deposition $\mathrm{ZrO}_{2}$ doped with HRP for fabrication of hydrogen peroxide biosensor. J. Biotechnol, 2007,128(3):567-575.

DOI:10.1016/j.jbiotec.2006.12.008 